\title{
ASPECTOS ESTRUTURAIS RELACIONADOS AO PROCESSO DE TROCA IÔNICA NO NIOBATO LAMELAR $\mathrm{K}_{4} \mathrm{Nb}_{6} \mathrm{O}_{17}$
}

Marcos A. Bizeto, Fernando P. Christino, Marina F. M. Tavares e Vera R. L. Constantino*

Instituto de Química, Universidade de São Paulo CP 26077, 05513-970, São Paulo - SP, Brasil

Recebido em 13/9/05; aceito em 21/3/06; publicado na web em 25/7/06

\begin{abstract}
STRUCTURAL ASPECTS RELATED TO THE ION EXCHANGE PROCESS IN LAYERED NIOBATE $\mathrm{K}_{4} \mathrm{Nb}_{6} \mathrm{O}_{17}$. The niobate with formula $\mathrm{K}_{4} \mathrm{Nb}_{6} \mathrm{O}_{17}$ has a layered structure formed by stacked negative sheets and exchangeable cations in the interlayer region. In this study we discuss some structural aspects related to the ion exchange in layered hexaniobate based on X-ray diffractometry and vibrational Raman spectroscopy data. Hexaniobate has two distinct interlayer regions and the potassium ions of one interlayer in particular are preferably exchanged by other cations, leading to an interstratified material.
\end{abstract}

Keywords: $\mathrm{K}_{4} \mathrm{Nb}_{6} \mathrm{O}_{17}$; ion exchange; intercalation.

\section{INTRODUÇÃO}

Os sólidos inorgânicos lamelares apresentam estrutura formada pela sobreposição organizada de camadas bidimensionais chamadas de lamelas. Entre essas camadas, existe um espaço livre denominado de região interlamelar. Esse espaço pode estar vazio, no caso do composto ser formado por lamelas eletricamente neutras, ou estar preenchido por íons que mantêm a eletroneutralidade do sistema, no caso das lamelas apresentarem excesso de cargas elétricas ${ }^{1}$.

$\mathrm{O}$ interesse em compostos com esse tipo de estrutura reside no fato de que a região interlamelar pode ser modificada de modo a abrigar espécies de diferentes naturezas, conferindo novas propriedades ao sistema a partir da interação hóspede-hospedeiro que se estabelece entre as partes. Nosso grupo tem se dedicado ao estudo dos niobatos lamelares em razão de algumas de suas propriedades (estabilidade química em meio ácido ou básico, caráter semicondutor, fotossensibilidade etc. $)^{2}$ e da alta disponibilidade do metal no Brasil.

Dentre as várias fases de niobatos lamelares conhecidas, temos utilizado o hexaniobato de fórmula $\mathrm{K}_{4} \mathrm{Nb}_{6} \mathrm{O}_{17}$, o qual é formado por camadas constituídas de unidades octaédricas distorcidas de $\mathrm{NbO}_{6}$, que estão ligadas entre si pelo compartilhamento de vértices e ares$\operatorname{tas}^{3}$. A região interlamelar é preenchida por íons de metais alcalinos $\left(\mathrm{K}^{+}, \mathrm{Rb}^{+}, \mathrm{Cs}^{+}\right)$que mantêm a eletroneutralidade do sistema, conforme a Figura 1. Esse sólido apresenta duas regiões interlamelares distintas designadas por regiões I e II. Essa diferenciação é feita não só em razão das regiões serem cristalograficamente diferentes, mas, também, por apresentarem propriedades distintas relacionadas com a intercalação de moléculas. Segundo estudo ${ }^{4}$ sobre mecanismos de hidratação da região interlamelar, apenas a região I pode ser hidratada. Essa diferença de comportamento entre as duas regiões faz com que a região I seja muito mais reativa frente à substituição dos cátions interlamelares por reações de troca iônica que a região II.

O processo de troca iônica no hexaniobato lamelar não é assunto novo. Lagaly e Beneke ${ }^{5}$ foram os primeiros a explorar a reatividade intracristalina do $\mathrm{K}_{4} \mathrm{Nb}_{6} \mathrm{O}_{17}$, promovendo a troca iônica do potássio interlamelar por uma série de cátions orgânicos (n-alquilamônios). Um outro estudo foi realizado por Kinomura e colaboradores ${ }^{6}$ empregando cátions simples mono- e divalentes. A troca iônica é um tópico relevante na química do hexaniobato lamelar, pois viabiliza

*e-mail: vrlconst@iq.usp.br

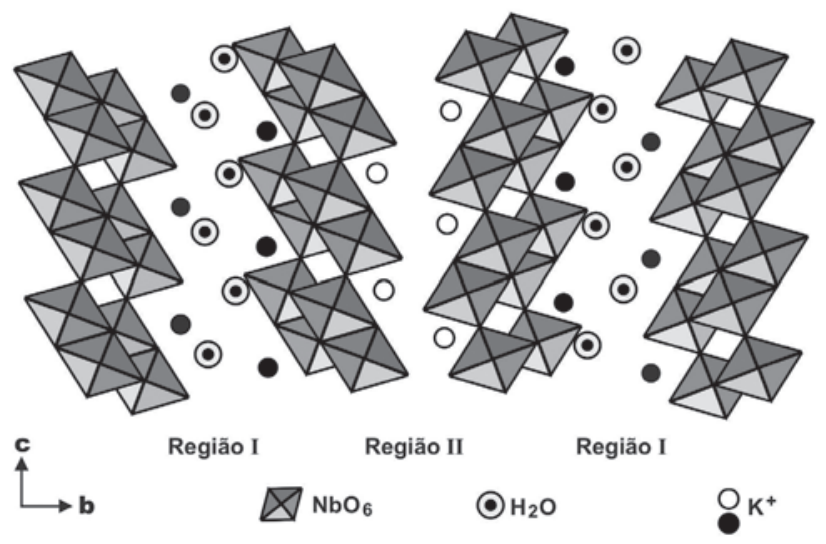

Figura 1. Representação esquemática da estrutura do hexaniobato lamelar de fórmula $\mathrm{K}_{4} \mathrm{Nb}_{6} \mathrm{O}_{17} \cdot 3 \mathrm{H}_{2} \mathrm{O}$. Adaptada da ref. 3

a obtenção de fases com cátions interlamelares diferentes dos apresentados anteriormente, tendo em vista a impossibilidade da síntese direta de tais fases através do método cerâmico.

A troca iônica alcançou novas perspectivas quando fotocatalisadores capazes de promover a fotólise da água em oxigênio e hidrogênio moleculares foram obtidos a partir da substituição do íon potássio interlamelar por complexos de níquel(II) e de platina(II), que foram posteriormente reduzidos $\mathrm{com}_{2}$, de modo a gerar nanopartículas metálicas na região interlamelar7. A produção e utilização de combustíveis mais limpos obtidos a partir de fontes renováveis é um campo bastante relevante atualmente e os fotocatalisadores sintetizados a partir do niobato lamelar apresentaram eficiência superior aos óxidos metálicos usualmente utilizados para tal finalidade. Entretanto, os fotocatalisadores constituídos de niobatos lamelares esbarram na desvantagem da pequena área superficial, algo em torno de poucos metros quadrados por gra$\mathrm{ma}^{2}$. A solução encontrada para o problema envolve a utilização de métodos capazes de promover a esfoliação dos niobatos lamelares ${ }^{8,9}$. Utilizando-se uma combinação adequada de cátion interlamelar e um solvente, é possível promover a separação total das lamelas do cristal, resultando em dispersões coloidais de lamelas esfoliadas ${ }^{9}$. As partículas esfoliadas podem ser reorganizadas não só de forma 
a gerar sólidos com elevada área superficial ${ }^{10}$, mas, também, permitem a obtenção de nanocompósitos ${ }^{11} \mathrm{e}$ filmes finos ${ }^{12}$ que mantêm as propriedades de troca iônica do niobato precursor. Recentemente, foi observado que as lamelas esfoliadas sob determinadas condições de $\mathrm{pH}$ e força iônica enrolam-se de maneira a produzir nanotubos ${ }^{13}$. Esse fato abre novos horizontes para aplicação dos niobatos lamelares, pois partículas tubulares são interessantes não só do ponto de vista de sua forma peculiar, mas, também, por apresentarem propriedades adequadas para a fabricação de dispositivos nanotecnológicos. Em um estudo publicado recentemente ${ }^{14}$, mostramos que as partículas tubulares mantêm as propriedades de troca iônica do niobato de partida, inclusive por espécies volumosas, gerando materiais de elevada área superficial.

No presente artigo, relatamos um estudo sobre a reatividade intracristalina do hexaniobato lamelar de potássio frente à troca iônica por cátions de diferentes tamanhos e cargas, e discutimos as modificações estruturais advindas do processo. Esse estudo é o ponto de partida para trabalhos futuros envolvendo a produção de catalisadores e fotocatalisadores de niobato tubulares contendo nanopartículas metálicas em seu interior.

\section{PROCEDIMENTO EXPERIMENTAL}

\section{Síntese do hexaniobato e reação de troca iônica}

$\mathrm{O} \mathrm{K}_{4} \mathrm{Nb}_{6} \mathrm{O}_{17}$ foi sintetizado através do método cerâmico, que consiste no aquecimento de uma mistura de $\mathrm{Nb}_{2} \mathrm{O}_{5}$ (Companhia Brasileira de Metalurgia e Mineração - CBMM) e $\mathrm{K}_{2} \mathrm{CO}_{3}$ (Merck), em proporções estequiométricas, a $1100{ }^{\circ} \mathrm{C}$ em cadinho de platina por $10 \mathrm{~h}^{15}$. A síntese foi feita em duas etapas de $5 \mathrm{~h}$ e, entre cada etapa, o material do cadinho foi novamente triturado para garantir a homogeneidade da mistura. Posteriormente, o material obtido foi lavado com água desionizada e seco em dessecador sob vácuo e contendo sílica gel como secante.

A reação de troca iônica foi realizada suspendendo-se $822 \mathrm{mg}$ do niobato em $25,0 \mathrm{~mL}$ de uma solução $400 \mathrm{mmol} / \mathrm{L}$ do cátion a ser trocado. Nesses experimentos foram utilizadas as soluções dos sais $\mathrm{NaCl}$ (Merck), $\mathrm{MgSO}_{4} .7 \mathrm{H}_{2} \mathrm{O}$ (Merck), $\mathrm{CuSO}_{4} .5 \mathrm{H}_{2} \mathrm{O}$ (Reagen), $\mathrm{CoSO}_{4} \cdot 7 \mathrm{H}_{2} \mathrm{O}$ (Aldrich), $\mathrm{NH}_{4} \mathrm{Cl}$ (Nuclear) e $\mathrm{Al}\left(\mathrm{NO}_{3}\right)_{3} \cdot 9 \mathrm{H}_{2} \mathrm{O}$ (Merck). $\mathrm{O}$ sistema foi deixado sob agitação e aquecimento a aproximadamente $85{ }^{\circ} \mathrm{C}$ por $16 \mathrm{~h}$ em sistema de refluxo. Os sólidos foram isolados por filtração, lavados com água desionizada e secos em dessecador sob vácuo contendo sílica gel. Tanto o filtrado quanto as frações de água usadas na lavagem foram guardados para quantificar a porcentagem de troca iônica por eletroforese capilar.

$\mathrm{O}$ niobato protônico $\mathrm{H}_{2} \mathrm{~K}_{2} \mathrm{Nb}_{6} \mathrm{O}_{17}$ foi sintetizado conforme procedimento relatado previamente. $\mathrm{O}$ niobato na forma potássica foi suspenso em uma solução de $\mathrm{HNO}_{3}(6 \mathrm{~mol} / \mathrm{L})$ e mantida em agitação sob aquecimento a $60{ }^{\circ} \mathrm{C}$ por 3 dias. Após esse período a solução de ácido foi substituída por outra recém-preparada e repetido o procedimento. A quantidade de prótons foi determinada por termogravimetria conforme procedimento descrito anteriormente ${ }^{16}$.

Os sólidos obtidos foram caracterizados por difratometria de raios X e espectroscopia vibracional Raman. Os difratogramas de raios $\mathrm{X}$ foram registrados em difratômetro Philips modelo MPD 1880 do Laboratório de Caracterização Tecnológica do Departamento de Engenharia de Minas (Poli-USP). O raio X é gerado por um ânodo de $\mathrm{Cu}(K \alpha)$, utilizando-se $40 \mathrm{kV}$ de tensão, $40 \mathrm{~mA}$ de corrente e fendas fixas. A preparação dos filmes foi feita colocando-se algumas gotas de uma suspensão aquosa do material a ser analisado no porta amostras de vidro, e deixando sob condições ambientes até a completa evaporação do solvente. A seguir, o porta amostras foi levado ao dessecador, onde ficou sob vácuo e com sílica-gel como secante por $24 \mathrm{~h}$. As micrografias foram registradas em microscópio eletrônico de transmissão de alta resolução JEOL, modelo JEM3010 ARP 300kV do Laboratório de Microscopia do Laboratório Nacional de Luz Síncrotron (Campinas - SP). A preparação da amostra consiste no gotejamento de uma suspensão do material em etanol sobre o porta amostras recoberto com uma camada de carbono. Os espectros Raman foram registrados em equipamento Raman Renishaw, do Laboratório de Espectroscopia Molecular do IQ-USP, usando laser com linha de excitação em 632,8 nm.

\section{Determinação da porcentagem de troca iônica por eletroforese capilar}

As soluções dos cátions recolhidas após o processo de troca iônica foram colocadas em balões volumétricos de $250 \mathrm{~mL}$ e seus volumes foram completados com água desionizada. $\mathrm{O}$ experimento de eletroforese capilar foi realizado em equipamento Applied Biosystems modelo 270A-HT com detector espectrofotométrico. O eletrólito empregado consistia em uma solução $5 \mathrm{mmol} / \mathrm{L}$ do cromóforo imidazol (Aldrich) em pH 5, e uma solução 5 mmol/L de ácido hidroxi-isobutírico (HIBA) (Aldrich) como agente complexante. A monitoração foi feita em 214 nm, sob tensão constante de $+15 \mathrm{kV}$. Para separar os sinais dos íons $\mathrm{NH}_{4}^{+}$e $\mathrm{K}^{+}$, foi utilizada solução $1 \mathrm{mmol} / \mathrm{L}$ do éter 18-coroa-6 (Aldrich), o qual complexa o potássio seletivamente, diminuindo sua mobilidade e tornando possível quantificá-lo na presença de outros cátions. As porcentagens de troca foram determinadas em duplicata com base na quantidade de potássio presente em cada solução, empregando uma curva de calibração previamente construída.

\section{RESULTADOS E DISCUSSÃO}

A investigação do processo de troca iônica no hexaniobato lamelar envolvendo íons inorgânicos foi realizada por poucos grupos de pesquisa $^{6,17,18}$. Segundo o estudo realizado por Kinomura e colaboradores $^{6}$, os íons potássio das duas regiões interlamelares podem ser totalmente substituídos por cátions monovalentes nas condições experimentais empregadas pelos autores. Já no caso de cátions de maior valência, a troca ocorre apenas na região I. Embora os resultados obtidos pelos autores suportem o comportamento acima, uma explicação a respeito do comportamento distinto das regiões interlamelares I e II em relação à troca iônica ainda não é conhecida.

Um outro estudo recente realizado por nosso grupo ${ }^{16}$ sobre a troca iônica do potássio interlamelar por $\mathrm{H}_{3} \mathrm{O}^{+}$mostrou que essa substituição ocorre apenas na região $\mathrm{I}$, originando um material interestratificado, cujo padrão de difração de raios X é bem característico. A troca iônica na região interlamelar II é algo difícil de ocorrer tendo em vista que a mesma não se hidrata facilmente ${ }^{4}$. $\mathrm{O}$ termo interestratificado é usado em mineralogia para descrever argilominerais formados por dois ou mais tipos de lamelas empilhadas de maneira ordenada ou não ${ }^{19}$, e pode ser empregado para outros sistemas lamelares.

As duas regiões interlamelares do hexaniobato lamelar apresentam diferenças cristalográficas, portanto, a análise do difratograma de raios $\mathrm{X}$ pode fornecer informações importantes sobre a troca iônica. A célula unitária do $\mathrm{K}_{4} \mathrm{Nb}_{6} \mathrm{O}_{17} \cdot 3 \mathrm{H}_{2} \mathrm{O}$ pertence ao sistema ortorrômbico e é formada pelo empilhamento de quatro lamelas ao longo do eixo cristalográfico b, que delimitam quatro regiões interlamelares (duas regiões I e duas regiões II) ${ }^{3}$. A espessura de cada lamela é estimada em 4,1 Å enquanto a região I, preenchida por $\mathrm{K}^{+}$hidratado, tem aproximadamente $5,8 \AA$ de altura e a região II tem $4,9 \AA^{6}$. O padrão de difração de raios $\mathrm{X}$ do niobato lamelar é mostrado na Figura 2.

Diferentemente da maioria dos compostos lamelares nos quais 


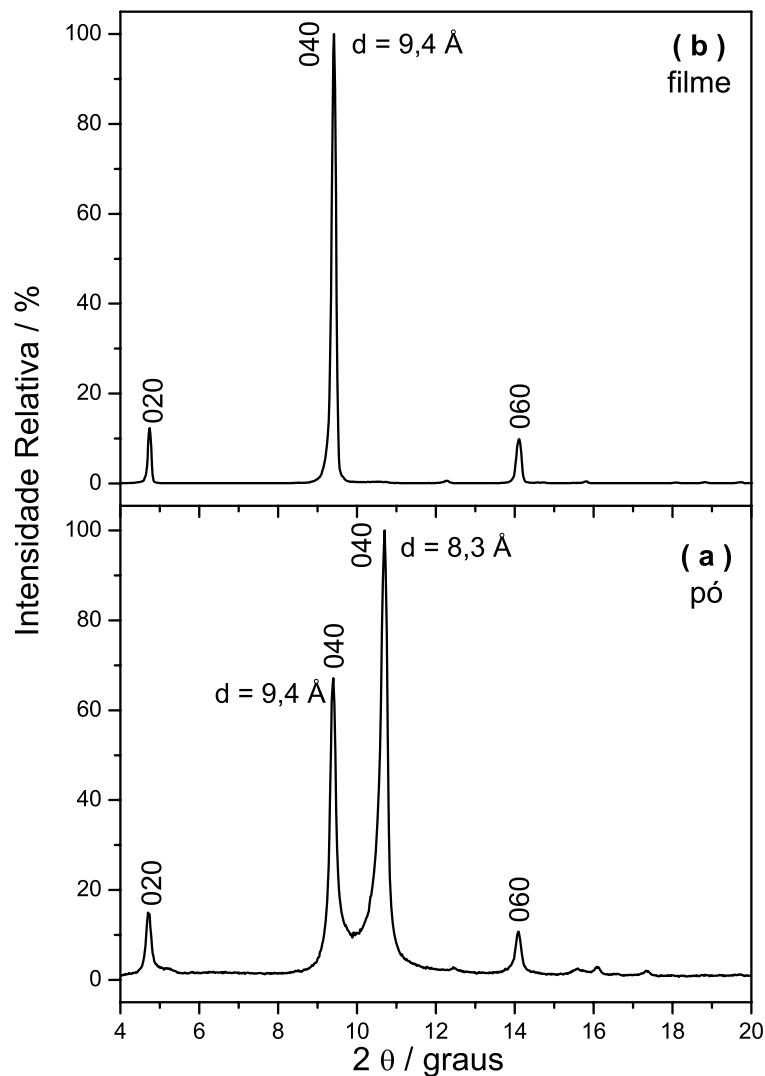

Figura 2. Difratogramas de raios $\mathrm{X}$ do $\mathrm{K}_{4} \mathrm{Nb}_{6} \mathrm{O}_{17}$ hidratado: (a) amostra na forma de pó compactado e (b) amostra na forma de filme orientado

o pico referente à primeira ordem de difração é o mais intenso, no hexaniobato de potássio hidratado o pico de difração (020) é menos intenso que o de segunda ordem (040). Acreditamos que esse comportamento seja devido à diferença estrutural das duas regiões interlamelares. As regiões I e II atuariam como duas fendas que, dependendo da abertura, podem gerar interferência construtiva ou destrutiva entre os raios $\mathrm{X}$ difratados. $\mathrm{O}$ pico da primeira ordem (020) é referente à difração de metade da célula unitária, o que corresponde às distâncias interplanares do conjunto de duas regiões interlamelares (uma região I e uma II). No caso dessas duas regiões apresentarem o mesmo espaçamento, a interferência seria totalmente construtiva e o pico 020 seria o mais intenso. Como essas regiões têm espaçamentos distintos, a interferência entre os raios difratados é parcialmente construtiva, o que resulta no aparecimento do pico 020 com baixa intensidade (Figura 2). O difratograma de raios $\mathrm{X}$ do $\mathrm{K}_{4} \mathrm{Nb}_{6} \mathrm{O}_{17}$ anidro não apresenta pico referente ao plano (020), corroborando com a proposta de que regiões I e II muito distintas geram interferência destrutiva. $\mathrm{O}$ pico referente à segunda ordem de difração (040) representa a distância interplanar de um quarto da célula unitária, o que daria o espaçamento de cada uma das regiões interlamelares. Sendo assim, seria de se esperar o aparecimento de dois picos de difração, um para cada região interlamelar, conforme mostra a Figura $2 \mathrm{a}$. Geralmente os difratogramas de raios $\mathrm{X}$ de materiais lamelares interestratificados não apresentam picos distintos de cada uma das fases que o formam e, sim, um único pico alargado. No caso do material ser formado por partes iguais das fases lamelares distintas empilhadas de maneira alternada, o valor do pico de difração corresponde aproximadamente à média dos espaçamentos interplanares das fases constituintes ${ }^{19}$. Contudo, devido ao hexaniobato de potássio ser um mate- rial muito cristalino, os picos de difração são intensos e estreitos, o que evita a sobreposição e permite a identificação das diferentes lamelas. $\mathrm{O}$ aparecimento dos picos das diferentes lamelas que constituem o niobato também depende da forma na qual a amostra é preparada para análise. A Figura $2 \mathrm{~b}$ apresenta o difratograma do niobato mostrado na Figura 2a, só que o sólido foi preparado para a difratometria a partir de uma suspensão aquosa, a qual após secagem forma um filme com partículas com alto grau de orientação preferencial. Nesse caso é observada uma grande intensificação dos picos referentes à difração dos planos orientados $(0 \mathrm{k} 0)$ e, por essa razão, o difratograma do material mostra apenas um único pico referente à distância interplanar 040 (Figura 2b).

Mesmo preparando a amostra para análise diretamente na forma de pó (compactado no porta amostras) ainda é observada uma alta orientação preferencial das partículas, evidenciada pela baixa intensidade dos picos referentes aos planos intracristalinos (h0l) na região de alto ângulo. Esse fato não pode ser atribuído à ausência ou à baixa cristalinidade da estrutura das lamelas já que, na imagem obtida por microscopia eletrônica de transmissão de alta resolução mostrada na Figura 3, é possível observar a presença de franjas de interferência resultantes dos planos atômicos bem definidos do retículo cristalino das lamelas no plano ac. Os espaçamentos entre essas franjas observadas na imagem coincidem com as dimensões a e c da célula unitária ortorrômbica do hexaniobato $(\mathrm{a}=$ $7,78 \AA$ e c $=6,46 \AA)^{3}$.

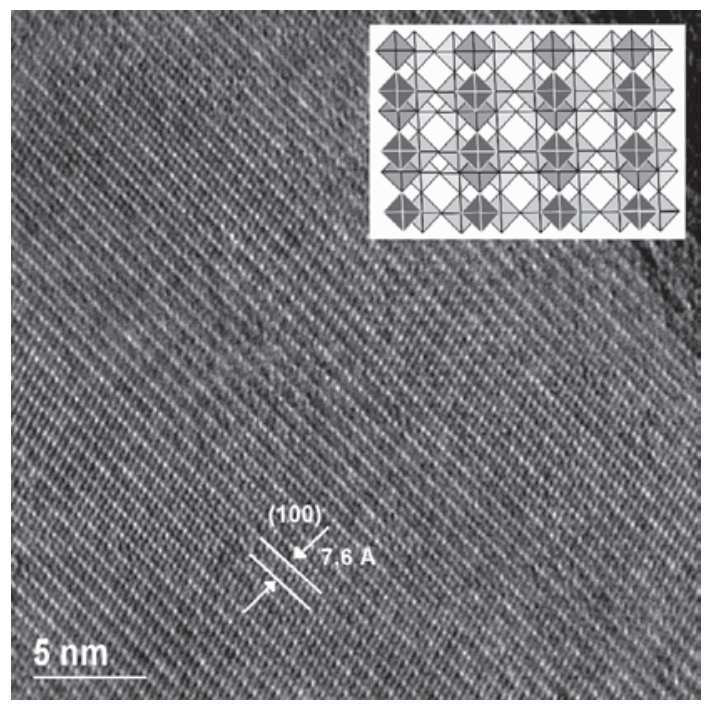

Figura 3. Micrografia de alta resolução de uma lamela do $\mathrm{K}_{4} \mathrm{Nb}_{6} \mathrm{O}_{17}$ ao longo do plano ac. $O$ detalhe mostra um esquema da estrutura que está sendo observada

A troca do potássio interlamelar por outros cátions foi avaliada por eletroforese capilar e os resultados são mostrados na Tabela 1. Nas condições em que foram realizados os experimentos, a porcentagem de troca foi inferior a 50\%, indicando que a substituição deve ter ocorrido apenas na região interlamelar I, já que a região interlamelar II não se hidrata facilmente ${ }^{4}$. Em alguns casos, como o dos íons $\mathrm{Cu}$ (II) e $\mathrm{Al}(\mathrm{III})$, a porcentagem de troca foi um pouco superior a $50 \%$. Em um estudo anterior ${ }^{17}$, no qual a porcentagem de troca de $\mathrm{Cu}$ (II) foi determinada por titulação complexométrica com EDTA, o resultado foi semelhante, indicando confiabilidade nos dados mostrados na Tabela 1.

A troca iônica também afeta a estrutura do niobato em razão dos diferentes tamanhos e cargas dos cátions utilizados na troca. $\mathrm{O}$ que se espera são mudanças nas posições dos picos referentes ao 
Tabela 1. Porcentagens de troca para os diferentes cátions estudados

\begin{tabular}{lcl}
\hline Cátion & \% de troca & Fórmula Proposta \\
\hline $\mathrm{H}_{3} \mathrm{O}^{+}$ & $50,0^{\mathrm{b}}$ & $\mathrm{K}_{2} \mathrm{H}_{2} \mathrm{Nb}_{6} \mathrm{O}_{17}$ \\
$\mathrm{NH}_{4}^{+}$ & 38,6 & $\mathrm{~K}_{2,5}\left(\mathrm{NH}_{4}\right)_{1,5} \mathrm{Nb}_{6} \mathrm{O}_{17}$ \\
$\mathrm{Na}^{+}$ & 41,4 & $\mathrm{~K}_{2,3} \mathrm{Na}_{1,7} \mathrm{Nb}_{6} \mathrm{O}_{17}$ \\
$\mathrm{Mg}^{2+}$ & 0,20 & $\mathrm{~K}_{4} \mathrm{Nb}_{6} \mathrm{O}_{17}$ \\
$\mathrm{Co}^{2+}$ & 41,5 & $\mathrm{~K}_{2,3} \mathrm{Co}_{0,8} \mathrm{Nb}_{6} \mathrm{O}_{17}$ \\
$\mathrm{Cu}^{2+}$ & 59,3 & $\mathrm{~K}_{1,6} \mathrm{Cu}_{1,2} \mathrm{Nb}_{6} \mathrm{O}_{17}$ \\
$\mathrm{Al}^{3+}$ & 52,8 & $\mathrm{~K}_{1,9} \mathrm{Al}_{0,7} \mathrm{Nb}_{6} \mathrm{O}_{17}$ \\
\hline
\end{tabular}

a) porcentagem calculada com base na quantidade de $\mathrm{K}^{+}$presente na suspensão após a reação de troca iônica; b) determinado através de termogravimetria, vide ref. 16

espaçamento entre as lamelas empilhadas $(0 \mathrm{k} 0)$ na região de baixo ângulo. Os difratogramas de raios $\mathrm{X}$ das amostras com os diferentes cátions estudados são mostrados na Figura 4. Para os cátions monovalentes, com exceção do $\mathrm{H}_{3} \mathrm{O}^{+}$, o pico de primeira ordem de difração (020) aparece em todos os difratogramas registrados. Já para cátions de valências superiores, esse pico não é observado. Como discutido anteriormente, o aparecimento do pico referente à primeira ordem de difração está relacionado com os espaçamentos das duas regiões interlamelares do hexaniobato, cuja diferença pode ou não causar a total extinção do pico 020. Sendo assim, consideraremos na análise apenas o pico mais intenso (040), relacionado ao espaçamento basal e que está presente em todos os difratogramas.

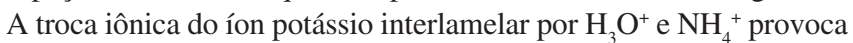
diminuição do espaçamento basal. Já no caso do íon $\mathrm{Na}^{+}$, embora o raio iônico seja menor que o do potássio, seu raio hidratado é maior, o que resulta no aumento do espaçamento basal ${ }^{20}$. Segundo os dados de eletroforese capilar, a extensão da troca por $\mathrm{Mg}^{2+}$ foi muito baixa, mas suficiente para causar modificações estruturais evi-

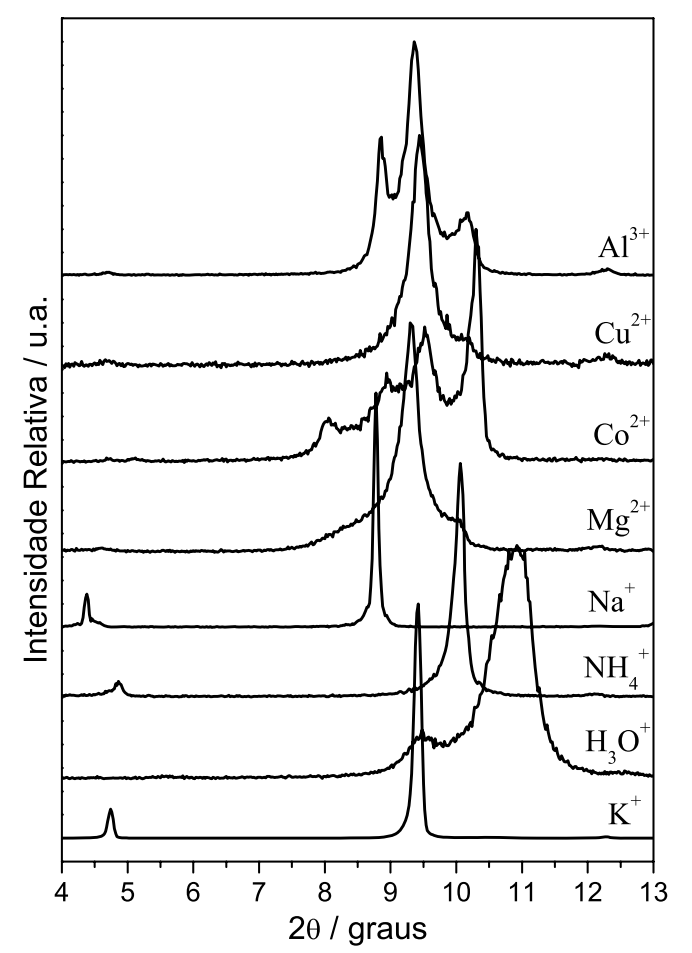

Figura 4. Difratogramas de raios $X$ do hexaniobato lamelar (filme orientado) após as reações de troca iônica denciadas pelo difratograma de raios $\mathrm{X}$ do material, o qual não apresenta deslocamento significativo do pico 040, porém o pico 020 não é mais observado. Para os outros cátions utilizados $\left(\mathrm{Cu}^{2+}\right.$, $\mathrm{Co}^{2+}$ e $\mathrm{Al}^{3+}$ ), o pico 020 também não é observado e o pico 040 apresenta-se desdobrado em vários picos, que podem ser atribuídos a fases com diferentes graus de hidratação. O desaparecimento do pico 020 quando o íon $\mathrm{K}^{+}$é substituído por cátions de valências superiores $\mathrm{a}+1$ já fora observado anteriormente para o hexaniobato, em um estudo no qual o potássio foi substituído por íons $\mathrm{Eu}(\mathrm{III})^{18}$. As distâncias interplanares referentes ao espaçamento basal $\mathrm{d}_{040}$ dos vários materiais são listados na Tabela 2.

Tabela 2. Espaçamentos basais referentes ao pico de difração 040 do hexaniobato lamelar com diferentes cátions interlamelares

\begin{tabular}{lc}
\hline Cátion Interlamelar & $\mathrm{d}_{040} / \AA$ \\
\hline $\mathrm{K}^{+}$ & 9,39 \\
$\mathrm{H}_{3} \mathrm{O}^{+}$ & 9,$33 ; 8,10$ \\
$\mathrm{NH}_{4}^{+}$ & 8,79 \\
$\mathrm{Na}^{+}$ & 10,1 \\
$\mathrm{Mg}^{2+}$ & 9,51 \\
$\mathrm{Co}^{2+}$ & 11,$0 ; 9,89 ; 9,29 ; 8,59$ \\
$\mathrm{Cu}^{2+}$ & 9,37 \\
$\mathrm{Al}^{3+}$ & 9,$98 ; 9,45 ; 8,70$ \\
\hline
\end{tabular}

Considerando que, dentre os cátions estudados, os íons $\mathrm{Al}^{3+} \mathrm{e} \mathrm{Cu}^{2+}$ apresentam a maior constante de hidrólise $\left(\mathrm{pK}_{\mathrm{h}}=5,14\right.$ e 7,53, respectivamente $)^{21}$, o fato de suas soluções possuírem espécies do tipo $\left[\mathrm{M}\left(\mathrm{H}_{2} \mathrm{O}\right)_{\mathrm{n}}(\mathrm{OH})_{\mathrm{m}}\right]^{\mathrm{x}-\mathrm{m}}$ (onde $\mathrm{x}$ corresponde à carga do cátion), pode estar relacionado com os valores de troca iônica determinados serem superiores a $50 \%$. O excesso de cátions $\mathrm{K}^{+}$trocado deve ser proveniente da região II e, por razões ainda não identificadas, a troca iônica do íon potássio da região (possivelmente por íons $\mathrm{H}_{3} \mathrm{O}^{+}$gerados no processo de hidrólise, conforme discussão adiante) está sendo favorecida pela presença das espécies hidrolisadas de alumínio e cobre.

A Figura 5 mostra os espectros vibracionais Raman do niobato precursor potássico e das fases que foram obtidas após as reações de troca iônica. Os niobatos lamelares são formados por octaedros $\mathrm{NbO}_{6}$ com diferentes graus de distorção. As principais bandas referentes ao estiramento $\mathrm{Nb}-\mathrm{O}$ aparecem na região compreendida entre 850 e $1000 \mathrm{~cm}^{-1}$ (para os octaedros com alto grau de distorção) e 500 e $700 \mathrm{~cm}^{-1}$ (para os octaedros pouco distorcidos) ${ }^{22}$. Bandas intensas e estreitas que ocorrem entre 900 e $1000 \mathrm{~cm}^{-1}$ são atribuídas ao estiramento $\mathrm{Nb}=\mathrm{O}$ (ligações $\mathrm{Nb}-\mathrm{O}$ terminais que apresentam caráter de dupla ligação). Essa ligação, voltada para a região interlamelar, deve sofrer influência do cátion interlamelar. O que se espera é que a constante de força da ligação diminua quanto maior for a interação do oxigênio terminal com os cátions interlamelares, resultando em um deslocamento da banda relativa ao $\mathrm{vNb}=\mathrm{O}$ para regiões de menor freqüência. A troca do $\mathrm{K}^{+}$por $\mathrm{H}_{3} \mathrm{O}^{+}$altera significativamente as intensidades relativas das bandas em comparação ao espectro do hexaniobato na forma potássica (Figura 5). A nova banda que surge em $935 \mathrm{~cm}^{-1}$ no espectro do niobato protônico $\mathrm{H}_{2} \mathrm{~K}_{2} \mathrm{Nb}_{6} \mathrm{O}_{17}$ (Figura 5) foi atribuída na literatura ${ }^{23}$ ao estiramento $\mathrm{Nb}=\mathrm{O}$ com maior constante de força que no precursor potássico. Porém, a dúvida que surge é como a ligação de hidrogênio dos grupos $\mathrm{Nb}=\mathrm{O}$ terminais com o $\mathrm{H}_{3} \mathrm{O}^{+}$é capaz de aumentar a constante de força da ligação metal-oxigênio, já que o esperado seria o contrário. Em nossos estudos ${ }^{9}$, temos observado que quando reagimos o niobato ácido com uma amina, a protonação da fase orgânica na região interlamelar provoca o desaparecimento da ban- 
da em $936 \mathrm{~cm}^{-1}$, o que nos fez atribuir tal banda à deformação angular do íon $\mathrm{H}_{3} \mathrm{O}^{+}$. Segundo dados de espectroscopia Raman ${ }^{24}$, essa banda se desloca de aproximadamente 1200 para $1050 \mathrm{~cm}^{-1}$ à medida que aumenta a concentração de ácido bromídrico em água (o que, conseqüentemente, diminui a interação de hidrogênio $\mathrm{H}_{2} \mathrm{O} \cdots \mathrm{H}_{3} \mathrm{O}^{+}$). Em sólidos contendo o íon hidrônio e ânions como $\mathrm{SbCl}_{6}^{-}$e $\mathrm{AsF}_{6}^{-}$, a banda de deformação angular do íon $\mathrm{H}_{3} \mathrm{O}^{+}$se desloca para a região de $950 \mathrm{~cm}^{-1}$, indicando um menor grau de interação com as cavidades em relação às soluções de $\mathrm{HBr}^{24}$. No caso do hexaniobato, o deslocamento observado para região de menor freqüência também sugere que a interação do íon $\mathrm{H}_{3} \mathrm{O}^{+}$com a superfície interna das lamelas é menor que aquela que se estabelece entre a água e esse íon.

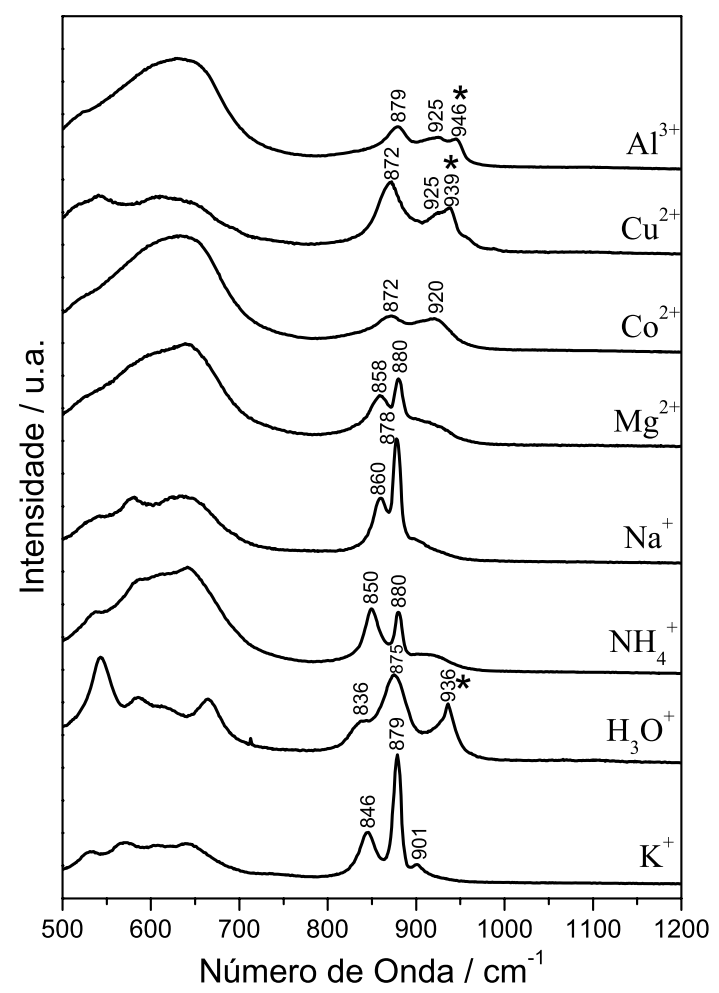

Figura 5. Espectros vibracionais Raman do hexaniobato lamelar após as reações de troca iônica. O asterisco indica a banda característica da presença de $\mathrm{H}_{3} \mathrm{O}^{+}$na região interlamelar

Nos espectros Raman dos niobatos contendo os cátions $\mathrm{Al}^{3+} \mathrm{e}$ $\mathrm{Cu}^{2+}$, observam-se bandas bem definidas em 946 e $939 \mathrm{~cm}^{-1}$, respectivamente, que podem ser atribuídas à presença do íon $\mathrm{H}_{3} \mathrm{O}^{+}$ proveniente da hidrólise do cátion na região interlamelar. Sabese que esses cátions sofrem hidrólise em meio homogêneo, gerando soluções aquosas ácidas ${ }^{24}$. O confinamento de cátions entre lamelas negativas, como a das argilas catiônicas (montmorilonita, hectorita, etc.), favorece a reação de hidrólise ${ }^{25}$. Em analogia ao que ocorre nas argilas, podemos propor que o processo de hidrólise dos íons $\mathrm{Al}^{3+}$ e $\mathrm{Cu}^{2+}$ (e provavelmente o $\mathrm{Co}^{2+}$ ) contidos entre as lamelas do niobato também seja favorecido. Observam-se também alterações na posição das bandas de absorção em $800-900 \mathrm{~cm}^{-1}$, atribuídas aos modos de vibração dos octaedros $\mathrm{NbO}_{6}$. Em relação ao hexaniobato de potássio, as bandas se deslocam para região de maior energia do espectro, sugerindo que a troca iônica provoca um aumento na distorção das unidades $\mathrm{NbO}_{6}$ que formam as lamelas.

\section{CONCLUSÕES}

O presente estudo mostrou que a troca iônica do potássio interlamelar por outros cátions simples é acompanhada de mudanças estruturais. Os dados da quantificação dos íons $\mathrm{K}^{+}$na suspensão após a reação de troca iônica sugerem que apenas os cátions presentes na região interlamelar I do hexaniobato foram substituídos, resultando em um sólido interestratificado. A presença e a intensidade do pico de difração referente à primeira ordem de difração dos planos lamelares (pico de índice 020) está relacionada com a carga e com o tamanho do cátion presente na região interlamelar I. Para cátions monovalentes com raios da mesma ordem de grandeza do íon potássio, o pico 020 é observado no difratograma, enquanto que para cátions de valências superiores e com raios menores que o do íon potássio, o pico de difração 020 não aparece nos difratogramas. A espectroscopia Raman sugere que cátions com alta razão carga/raio, como o $\mathrm{Al}^{3+}$ e o $\mathrm{Cu}^{2+}$, sofrem hidrólise na região interlamelar gerando íons $\mathrm{H}_{3} \mathrm{O}^{+}$que apresentam uma banda de deformação angular em aproximadamente $940 \mathrm{~cm}^{-1}$. A troca iônica também parece provocar um aumento da distorção das unidades $\mathrm{NbO}_{6}$ que formam as lamelas.

\section{AGRADECIMENTOS}

À FAPESP e ao CNPq pelo apoio financeiro e pelas bolsas concedidas, à CBMM por ter cedido o óxido de nióbio usado na síntese do niobato lamelar, à Profa. Dra. D. L. A. de Faria (Laboratório de Espectroscopia Molecular do IQ-USP) pelo registro dos espectros Raman e, também, ao Laboratório de Microscopia Eletrônica do Laboratório Nacional de Luz Síncrotron (LNLS), em Campinas-SP, pela concessão de horas de uso do microscópio e pelo apoio técnico (projeto TEM-3800).

\section{REFERÊNCIAS}

1. Schoonheydt, R. A.; Pinnavaia, T. J.; Lagaly, G.; Gangas, N.; Pure Appl. Chem. 1999, 71, 2367; Alberti, G.; Costantino, U. Em Solid State Supramolecular Chemistry: Two and Three - Dimensional Inorganic Networks; Alberti, G.; Bein, T., eds., Comprehensive Supramolecular Chemistry, Pergamon: Nova York, 1996, vol. 7, cap. 1.

2. Bizeto, M. A.; Tese de Doutorado, Universidade de São Paulo, Brasil, 2003.

3. Gasperin, M.; Bihan, M. T.; J. Solid. State Chem. 1980, 33, 83.

4. Gasperin, M.; Bihan, M. T.; J. Solid. State Chem. 1982, 43, 346.

5. Lagaly, G.; Beneke, K.; J. Inorg. Nucl. Chem. 1976, 38, 1513.

6. Kinomura, N.; Kumada, N.; Muto, F.; J. Chem. Soc., Dalton Trans 1985, 2349.

7. Kudo, A.; Sayama, K.; Tanaka, A.; Asakura, K.; Domen, K.; Maruya, K.; Onishi, T.; J. Catal. 1989, 120, 337; Sayama, K.; Tanaka, A.; Domen, K.; Maruya, K.; Onishi, T.; J. Catal. 1990, 124, 541; Sayama, K.; Tanaka, A.; Domen, K.; Maruya, K; Onishi, T.; J. Phys. Chem. 1991, 95, 1345; Ikeda, S.; Tanaka, A.; Shinohara, K.; Hara, M.; Kondo, J. N.; Maruya, K.; Domen, K.; Microporous Mesoporous Mater. 1997, 9, 253; Sayama, K.; Yase, K.; Arakawa, H.; Asakura, K.; Tanaka, A.; Domen, K.; Onishi, T.; J. Photochem. Photobiol., A 1998, 114, 125.

8. Keller, S. W.; Kim, H. N.; Mallouk, T. J.; J. Am. Chem. Soc. 1994, 116, 8817 .

9. Bizeto, M. A.; Constantino, V. R. L.; Mater. Res. Bull. 2004, 39, 1811; Shiguihara, A. L.; Dissertação de Mestrado, Universidade de São Paulo, Brasil, 2004.

10. Domen, K.; Ebina, Y.; Ikeda, Tanaka, A.; Kondo, J. N.; Maruya, K.; Catal. Today 1996, 28, 167; Abe, R.; Shinohara, K.; Tanaka, A.; Hara, M.; Kondo, J. N.; Domen, K.; Chem. Mater. 1997, 9, 2179; Abe, R.; Hara, M.; Kondo, J. N.; Domen, K.; J. Mater. Res. 1998, 13, 861.

11. Bizeto, M. A.; de Faria, D. L. A.; Constantino, V. R. L.; J. Mater. Sci. Lett. 1999, 18, 643; Bizeto, M. A.; de Faria, D. L. A.; Constantino, V. R. L.; J. Mater. Sci. 2002, 37, 265.

12. Abe, R.; Hara, M.; Kondo, J. N.; Domen, K.; Chem. Mater. 1998, 10, 1647; Abe, R.; Ikeda, S.; Kondo, J. N.; Hara, M.; Domen, K.; Thin Solid Films 1999, 343-344, 156.

13. Saupe, G. B.; Waraksa, C. C.; Kim, H. N.; Han, Y. J.; Kaschak, D. M., Skinner, D. M.; Mallouk, T. E.; Chem. Mater. 2000, 12, 1556. 
14. Bizeto, M. A.; Constantino, V. R. L.; Microporous Mesoporous Mater. 2005, $83,212$.

15. Nakato, T.; Kuroda, K.; Kato, C.; Chem. Mater. 1992, 4, 128.

16. Bizeto, M. A.; Constantino, V. R. L.; Mater. Res. Bull. 2004, 39, 1729.

17. Nunes, L. M.; de Souza, A. G.; de Farias, R. F.; J. Alloys Compd. 2001, 319, 94

18. Constantino, V. R. L.; Bizeto, M. A.; Brito, H. F.; J. Alloys Compd. 1998, $278,142$.

19. Brindley, G. W.; Brown, G.; Crystal Structures of Clay Minerals and Their X-Ray Identification, Mineralogical Society: Londres, 1984, cap. 4.

20. Lee, J. D.; Concise Inorganic Chemistry, $5^{\text {th }}$ ed., Chapman \& Hall: Londres, 1996.
21. Huheey, J. E.; Keiter, E. A.; Keiter, R. L.; Inorganic Chemistry: Principles of Structure and Reactivity, $4^{\text {th }}$ ed., Harper Collins College Publishers: Nova York, 1993.

22. Jehng, J. M.; Wachs, I. E.; Chem. Mater. 1991, 3, 100.

23. Kudo, A.; Sakata, T.; J. Phys. Chem. 1996, 100, 17323

24. Guiguere, P. A.; Gullot, J. G.; J. Phys. Chem. 1982, 86, 3231; Christe, K. O.; Schack, C. J.; Wilson, R. D.; Inorg. Chem. 1975, 14, 2224.

25. Carrado, K. A. Em Handbook of Layered Materials; Auerbach, S. M.; Carrado, K. A.; Dutta, P. K., eds.; Marcel Deckker: Nova York, 2004, cap. 1. 